\title{
VISIBILIZAÇÃO RADIOGRÁFICA DE TODO O SISTEMA VASCULAR ENCEFÁLICO MEDIANTE INJEÇÃO DE CONTRASTE EM UMA ÚNICA ARTÉRIA: PAN-ANGIOGRAFIA CEREBRAL
}

\author{
José Zaclis *
}

E sabido que, apesar das anastomoses existentes entre as três fontes arteriais que irrigam o encéfalo - carótidas internas e sistema vértebrobasilar - o sangue de cada uma dessas fontes sangüineas irriga, em condições normais, território encefálico mais ou menos estanque. Assim, quando uma substância de contraste é injetada em um dêsses troncos arteriais, tornam-se visíveis, na maioria dos casos, apenas os ramos de distribuição dêsse vaso.

Em patologia neurológica há eventualidades nas quais é necessária a visibilização da maior parte ou de todo o sistema vascular encefálico, exigindo injeçōes sucessivas de contraste em cada uma das fontes arteriais do encéfalo mediante três punções arteriais, duas nas carótidas e uma na artéria vertebral. Além disso, para o estudo radiológico de cada grupo vascular, são necessárias pelo menos duas incidências diferentes, ântero-posterior e perfil, o que exige duas injeções de contraste em cada artéria.

Tese para concurso à Docência Livre de Clínica Neurológica na Fac. Med. da Univ. de São Paulo (novembro de 1958).

* Assistente extranumerário da Clinica Neurológica da Fac. Med. da Univ. de São Paulo (Prof. Adherbą Tolosa); neurorradiologista do Hospital das Clínicas.

Nota do autor - Trabalhar na Clinica Neurológica da Faculdade de Medicina da Universidade de São Paulo é um privilégio: a harmonia no trabalho, aliada ao espirito de amizade e de lealdade reinante entre os elementos que o constituem, conferem a êsse Serviço as características de ambiente apropriado para trabalho proficuo. Esta tese, um dos frutos dessas condições ambientais, impõe a consignação de agradecimentos a todos os colegas que trabalham nessa Clínica. Agradecemos ao Prof. Raphael Penteado de Barros, mestre e amigo, a generosa acolhida na Secção de Radiodiagnóstico; ao pessoal técnica dessa Secção, nossa gratidão pelo valioso auxílio e eficiente colaboração no trabalho diário. Todos os elementos do Serviço de Anestesia do Hospital das Clínicas a quem devemos boa parte do êxito dêste trabalho merecem nosso profundo reconhecimento; ao Dr. Antonio Pereira de Almeida, elemento de elite dêsse Serviço, homem de idéias a quem tanto devemos, consignamos um agradecimento especial. 
Aos inconvenientes das punções arteriais múltiplas e da necessidade de, pelo menos, seis injeçōes de contraste para a visibilização de todos os grupos vasculares do encéfalo em dois planos, acresce a circunstância de que a punção da artéria vertebral pode oferecer dificuldades não raro intrasponíveis. A êsses inconvenientes podem ser acrescidos outros, de ordem secundária, como sejam o tempo despendido pelo pessoal técnico, a irradiação reiterada do paciente - particularmente quando são empregadas seriografias rápidas - e o elevado custo do material.

Assim, julgamos oportuno o presente trabalho, em que justificamos o emprêgo de processo pelo qual podem ser visibilizados todos os vasos encefálicos mediante injeção de contraste ùnicamente por uma das artérias carótidas; essencialmente, procuramos demonstrar que, baixando consideràvelmente a pressão arterial sistêmica, é possivel, em grande número de casos, tornar visivel todo o sistema vascular encefálico mediante injeção de contraste apenas por via carotídea.

A origem da presente tese prende-se ao estudo de 22 angiografias por via carotídea, nas quais, além dos vasos próprios do território da artéria na qual o contraste fôra injetado, foram visibilizadas também artérias pertencentes ao sistema carotídeo do lado oposto e/ou ao sistema vértebro-basilar 18. Casos como êsses foram também observados por Egas Moniz e col. ${ }^{9}$, van der Zwan ${ }^{14}$ e outros.

Apesar da importância decisiva que tiveram os $\mathbf{5}$ casos de Egas Moniz na história da angiografia do sistema vértebro-basilar, êste autor não se preocupou em esmiuçar as razões da passagem de contraste para a artéria basilar e seus ramos; êle admitia que tivesse havido, nesses casos, refluxo do contraste, injetado na carótida, até a artéria subclávia, de onde teria sido levado pela corrente da artéria vertebral. Van der Zwan interpretou a presença de contraste na artéria basilar e seus ramos em carotidoangiografias como decorrente de trombose das duas artérias vertebrais ou da extremidade inferior do próprio tronco basilar. Hamby 4 , Krayenbuhl 7, Shapiro e Peyton "1, Curtis ${ }^{2}$, Torkildsen ${ }^{13}$ e Ribe Portugal ${ }^{10}$ também referem casos semelhantes, sem, contudo, cogitarem da interpretaçāo do achado radiológico.

Analisando nossas angiografias carotídeas nas quais fôra visibilizado o tronco basilar e revendo os trabalhos dos autores mencionados, fomos levados a admitir mecanismo diferente daqueles sugeridos por Egas Moniz e van der Zwan.

O deslocamento retrógrado do contraste no interior da carótida, admitido por Egas Moniz, pode ocorrer nos casos de interrupção da corrente sangüinea pela oclusão dessa artéria a montante do ponto de penetração da agulha. A penetração de contraste nos vasos do sistema vértebro-basilar via artéria vertebral, em conseqüência de corrente retrógrada produzida pela injeção de contraste em carótida ocluída, foi observada em dois casos que tivemos oportunidade de registrar ${ }^{15}$; nesses casos, a imagem da carótida primitiva terminava no ponto da oclusão e a artéria vertebral era visivel em todo o segmento cervical apanhado na radiografia. Entretanto, nos casos de Egas Moniz não é possivel admitir a existência de oclusão carotídea, pôsto que os ramos desta artéria são visíveis nos angiogramas apresentados por êsse pesquisador. Por outro lado, admitindo que o contraste houvesse 
entrado no tronco basilar via artéria vertebral, a imagem desta deveria ser visivel, o que não ocorreu nesses casos.

Também a trombose das artérias vertebrais ou da extremidade inferior do tronco basilar, sugerida por van der Zwan ${ }^{14}$, embora passivel de determinar o enchimento de tronco basilar via artéria comunicante posterior, não constitui necessàriamente o mecanismo a ser invocado em todos os casos, sendo mesmo inadmissivel na maioria dêles. O fato de ter sido inconstante o enchimento do tronco basilar em injeções sucessivas de contraste no mesmo paciente na maior parte dos nossos casos, vem em abono do que acabamos de afirmar. Além disso, o enchimento do território carotídeo do lado oposto, observado nesses casos, não pode ser relacionado a uma oclusāo do tronco basilar ou das artérias vertebrais.

Segundo nosso modo de ver, o enchimento do sistema vértebro-basilar e dos ramos da carótida interna contralateral em angiografias carotídeas $\dot{e}$ devido a uma queda acentuada da pressão arterial $e$ do fluxo sangüineo encefálico, causada pela injeção do contraste.

$\mathrm{Na}$ interpretação do mecanismo responsável pela visibilização do tronco basilar e seus ramos em arteriografias carotídeas é necessário considerar duas condições: a via seguida pelo contraste e os fatôres que levam o contraste a seguir essa via.

Já vimos que a via sugerida por Egas Moniz pressupõe a existência de bloqueio da carótida e não pode ser admitida tanto nos casos dêsse autor como nos nossos, pelas razões já expostas. Também não é possivel, nas angiografias de nossa série, admitir a existência de vias anômalas estabelecendo anastomoses entre a carótida interna e o tronco basilar, como nos casos de persistência da artéria trigeminal, ou como nos casos de artéria vertebral originária da carótida, anomalias essas que seriam fàcilmente visiveis nas radiografias.

Excluídas a artéria vertebral e as mencionadas anomalias arteriais como vias de chegada para o interior do tronco basilar e seus ramos do contraste proveniente da carótida, só resta a artéria comunicante posterior que, ligando entre si a carótida interna e a artéria cerebral posterior, comunica o sistema carotídeo com o sistema vértebro-basilar. De fato, a artéria comunicante posterior é calibrosa e bem visivel em todos os 22 casos de nossa série acima referida. A artéria comunicante posterior é, pois, a via pela qual passa o contraste da carótida para o sistema vértebro-basilar, da mesma forma que a comunicante anterior permite a passagem do contraste de um sistema carotideo para o outro.

A resposta ao segundo item - quanto aos fatôres que, em alguns casos, levam o contraste a seguir essa via - nos foi sugerida pela interpretação dos fatos que ocorreram em dois pacientes, nos quais, durante angiografia por via carotídea, houve enchimento de todo o sistema vascular encefálico: referimo-nos às observações $n^{9} 4$ (L. M. F.) e $n^{9} 18$ (M. E. L.), expostas em trabalho anterior 18 .

No primeiro caso (L. M. F.), tratava-se de mulher com 39 anos de idade, portadora de hipertensão arterial que, um mês antes da internação, sofrera icto, ficando com hemiplegia esquerda. Durante o período de internação a pressão arte- 
rial oscilou entre $100 \times 70$ e $140 \times 90 \mathrm{~mm} \mathrm{Hg}$. O electrocardiograma revelou sinais de fibrilação auricular e extrassistolia ventricular; havia, cllnicamente, sinais de miocardiosclerose. Ao ser feita a angiografia cerebral via carótida direita, na incidência lateral, correspondente à segunda injeção de contraste, houve penetração do mesmo nas artérias do território da carótida interna, na comunicante posterior ipsolateral e no tronco basilar e seus ramos (fig. 1). Na radiografia em incidência sagital não tinha havido contrastação do tronco basilar. Logo após a segunda injeção de contraste, o anestesista verificou que a paciente entrara sủbitamente em apnéia com parada cardíaca; após violento golpe com a mão espalmada aplicado no precórdio da paciente, seu coração voltou a pulsar, embora a apnéia persistisse, exigindo respiração artificial.

No segundo caso (M, E. L.), tratava-se de menina de 18 meses de idade, que apresentava insuficiência cardiaca de causa não esclarecida. Quinze dias depois de sua internação apresentou hemiplegia direita e rigidez de nuca sem distúrbio da consciência. Pressão arterial $130 \times 70 \mathrm{~mm}$ Hg. Ao ser feita angiografia cerebral via carótida esquerda, em virtude da insuficiência cardiaca, foi estabelecjdo contrôle continuo das condiçōes cardiocirculatórias. Logo após a primeira injeção de contraste (10 ml de Nosylan a $35 \%$ ) houve bradicardia, que se acentuou ràpidamente, ocorrendo parada cardiaca, poucos segundos depois. Antes, porém, que qualquer medida de ressuscitação fôsse tomada, o coração voltou a se contrair, restabelecendo-se ràpidamente o ritmo cardiaco. Apesar dêsse acidente, foi deliberado terminar o exame. Foi feita nova injecão de $10 \mathrm{ml}$ de Nosylan, não sendo registrada qualquer modificação das condições circulatórias. O exame das radiografias mostrou que, por ocasião da primeira injeção, isto é, quando ocorreu bradicardia
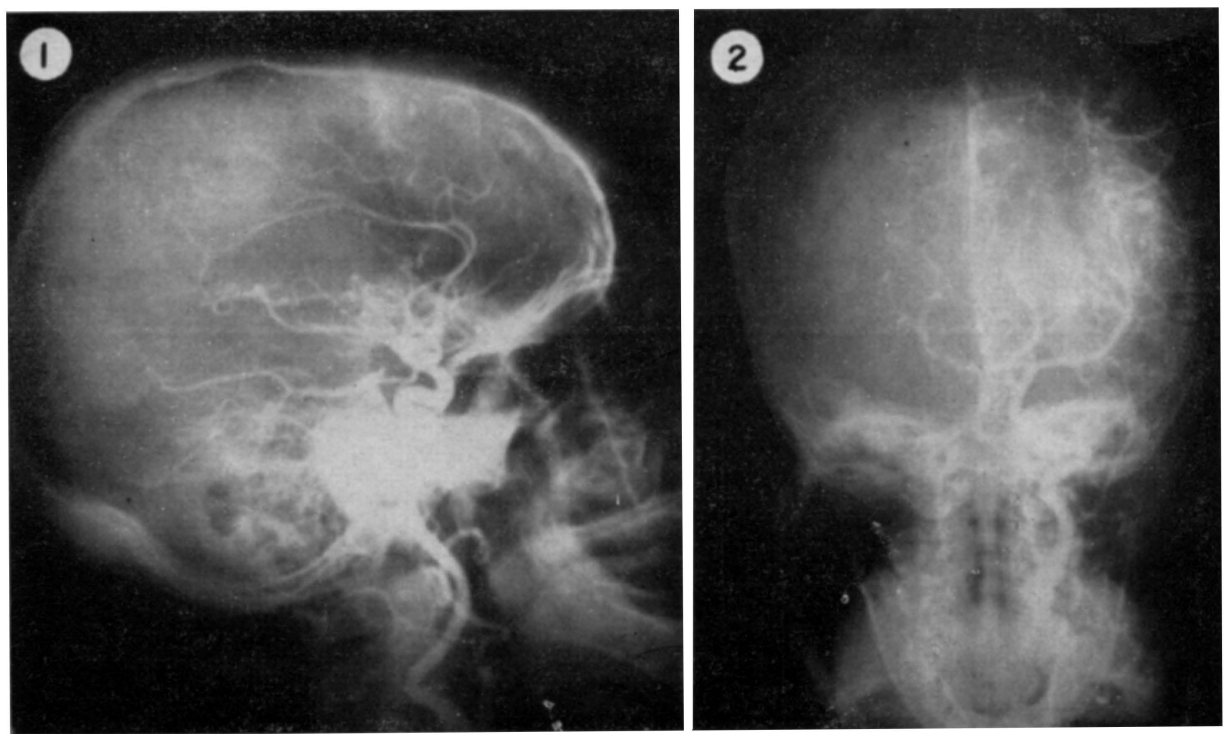

Fig. 1 - Caso 4, relatado em trabalho anterior ${ }^{18}$. Angiografia cerebral mostrando visibilização do tronco basilar e seus ramos pela segunda dose de contraste injetado na carótida direita.

Fig. 2 - Caso 19, relatado em trabalho anterior ${ }^{18}$. Angiografia cerebral mostrando visibilização da porção rostral das artérias vertebrais, do tronco basilar e de seus ramos pela primeira dose de contraste injetada na carótida esquerda. 
progressiva e parada cardiaca, houve penetração do contraste nas artérias do território carotídeo e na artéria comunicante posterior ipsolateral, enchendo o tronco basilar e apreciável extensão de ambas as artérias vertebrais. Entretanto, no arteriograma em incidência lateral (segunda injeção), quando não foram assinalados distúrbios circulatórios, não houve penetração do contraste no tronco basilar e nas artérias vertebrais (fig. 2). O exame foi repetido após um mês, tendo o resultado sido normal, sob todos os aspectos.

Nos dois casos que acabam de ser expostos, a razão da passagem do contraste da carótida para outros territórios vasculares encefálicos reside, a nosso ver, na grande diferença entre a pressão na carótida onde o contraste foi injetado e a pressão nas demais fontes arteriais do encéfalo: nestas últimas, a pressão era baixa em virtude da acentuada diminuição da pressão sistêmica; na carótida, onde estava atuando a pressão mecânica exercida pelo operador, a pressão era elevada. Em ambos os casos é patente a relação entre causa (parada cardíaca) e efeito (visibilização de todo o sistema vascular encefálico).

Quanto ao mecanismo desencadeante da bradicardia e da parada cardiaca, considerando a subitaneidade de sua instalação e sua curta duração e reversibilidade, fomos levados a admitir que as modificações circulatórias observadas nos casos L. M. F. e M. E. L. foram devidas a um mecanismo reflexo de tipo vagal. Assim sendo e considerando a semelhança, do ponto de vista angiográfico, entre êsses dois casos e os restantes da série referida no trabalho acima citado, pareceu-nos licito admitir que, em todos êles, tivesse havido baixa acentuada da pressão arterial e, eventualmente, parada cardíaca, distúrbios que, tendo sido reversiveis e de curta duração, passaram despercebidos na maioria dos casos.

Julgando que o contraste injetado sob forte pressão na carótida aumentasse a pressão intra-arterial, determinando distensão das paredes vasculares, admitimos, a principio, que as modificações circulatórias mencionadas fôssem devidas a um reflexo hiperativo do seio carotídeo.

Como é sabido, o reflexo do seio carotídeo, exaustivamente estudado por Heymans e col..$^{5}$, constitui um dos mecanismos de proteção do encéfalo contra variaçōes nocivas da pressão arterial sistêmica: o aumento brusco dessa pressão determina distensāo das paredes do seio carotídeo, excitando os corpúsculos barossensiveis existentes nessas paredes; como resposta a èsse estimulo há queda imediata e moderada da pressão arterial, com ligeira bradicardia. Estes efeitos são, no geral, passageiros; há, porém, individuos cujo seio carotídeo é hipersensível e nos quais qualquer estímulo desencadeia uma resposta exuberante, caracterizada por hipotensão arterial e acentuada bradicardia, que pode, por vêzes, chegar até à parada cardiaca. Trata-se, nesses casos, do chamado reflexo hiperativo do seio carotídeo.

Tendo em conta estas e outras propriedades do reflexo do seio carotídeo observadas por Heymans (variabilidade da resposta ao mesmo estimulo no mesmo individuo, uni ou bilateralidade do seio hipersensivel, facilitação do reflexo por anestesia geral), julgamos que êste seria o mecanismo das modificaçōes circulatórias observadas nos casos acima relatados, sendo a excitação do seio carotídeo produzida pela injeção do contraste sob pressão.

Entretanto, para poder atribuir em definitivo ao reflexo do seio carotídeo a responsabilidade das modificaçōes circulatórias (queda tensional e bradicardia) ne- 
cessárias para que o contraste injetado em uma das carótidas penetre em todo o sistema arterial encefálico, julgamos ser imprescindivel demonstrar que durante a injeção do contraste há, realmente, aumento de pressão intracarotídea.

Para isso inserimos duas agulhas na carótida primitiva de um paciente, ligando uma delas a um sistema de registro de pressão e injetando $15 \mathrm{ml}$ de Nosylan a $35 \%$ pela outra; o resultado não foi favorável à hipótese que formuláramos, pois não observamos qualquer variação de nivel tensional no registro obtido (fig. 3). O mesmo fato foi observado por Greitz ${ }^{3}$, que empregou método análogo.

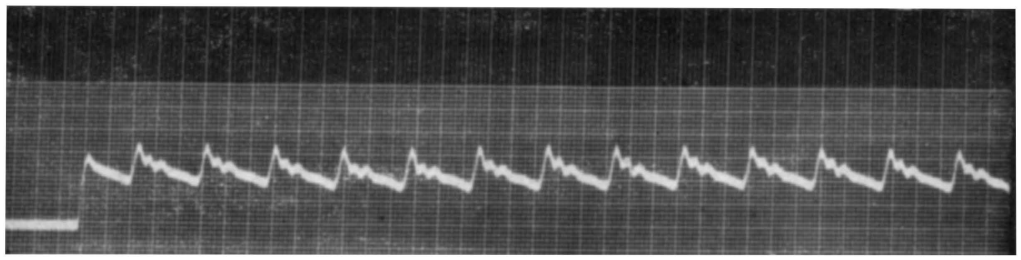

Fig. 3 - Registro da pressio intracarotidea antes, durante e depois da injecão de $15 \mathrm{ml}$ de Nosylan: nenhuma variacão tensional.

Por outro lado, há observaçōes que demonstram a possibilidade de desencadear distúrbios circulatórios semelhantes aos do reflexo do seio carotídeo sem a participação dêste seio: tivemos a oportunidade de observar um vaso de visibilização das artérias cerebrais do território carotideo pelo contraste injetado em uma das artérias vertebrais (fig. 4); Greitz observou hipotensão arterial e bradicardia em pacientes submetidos à angiografia cerebral, nos quais o contraste era injetado através de agulha inserida na carótida interna longe do seio carotídeo.

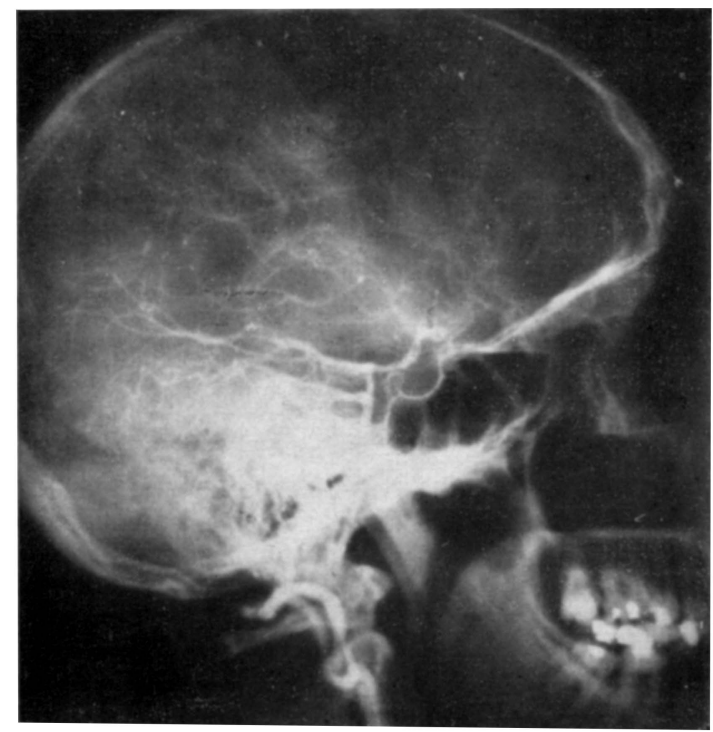

Fig. 4 - Angiografia cerebral via artéria vertebral direita, mostrando passagem de contraste para as artérias do território carotídeo através da arteria comunicante posterior do mesmo lado. 
Diante dêstes fatos não podemos insistir em que o reflexo do seio carotídeo seja responsável pelas modificações circulatórias por nós observadas. Segundo Greitz $^{3}$ e outros ${ }^{8}$, tratar-se-ia de um reflexo desencadeado pela ação da substância radiopaca sôbre estruturas encefálicas reguladoras da vasomotricidade. Esta hipótese parece lógica e bem fundamentada; entretanto, ela ainda não foi demonstrada, pois não foram identificadas as vias dêste arco reflexo.

Pelo que acaba de ser exposto verifica-se que faltam ainda elementos para uma resposta integral ao segundo quesito que formulamos, indagando sôbre as razões determinantes da hipotensão arterial e da bradicardia com eventual parada cardíaca. As modificações circulatórias responsáveis pela passagem do contraste de uma das carótidas para todos os vasos do encéfalo foram verificadas de modo objetivo nos casos relatados atrás; entretanto, o mecanismo desencadeante dessas modificações circulatórias permanece no terreno das hipóteses. Também não é possível, a rigor, afirmar que as mesmas modificações circulatórias tenham ocorrido nos casos restantes da série que relatamos em trabalho anterior ${ }^{18}$. Entretanto, podemos afirmar que a visibilização de todo o sistema vascular encefálico pelo contraste injetado em uma das carótidas pode ser obtida mediante redução considerável da pressão arterial sistêmica.

\section{PAN-ANGIOGRAFIA CEREBRAL}

Pan-angiografia cerebral é a designação que propomos para a visibilização de todo o sistema vascular encefálico mediante injeção de contraste em apenas uma das carótidas.

A visibilização de todos os vasos do encéfalo tornou-se possivel graças à hipotensão arterial induzida durante a injeção da substância radiopaca.

Indução da hipotensão arterial - Para demonstrar que, reduzindo consideràvelmente a pressão arterial do paciente e injetando substância opaca em uma das carótidas, o contraste penetra em todo o sistema vascular encefálico, lançamos mão, em primeiro lugar, de drogas do grupo dos ganglioplégicos. Entretanto, a hipotensão arterial produzida por êsses agentes farmacológicos não deu os resultados esperados; os efeitos dessas drogas não são sempre proporcionais às doses administradas em cada caso; há interferência de fatôres individuais, tornando necessárias, às vêzes, quantidades de ganglioplégicos que ultrapassariam os limites de segurança. Por estas razões, e tendo em vista evitar acidentes desagradáveis, êste método foi abandonado.

O bloqueio da corrente circulatória por meio da hiperpressão intrapulmonar pareceu-nos o método de escolha para a realização do que tínhamos em mira.

A história das modificacões circulatórias decorrentes de hiperpressão intrapulmonar remonta ao século XVII; Valsalva observou que, quando um paciente espirrava, se a corrente expiratória fôsse obstada, havia aumento de pressão intratorácica que, atuando sôbre o coração e grandes vasos, determinava diminuição do fluxo sangüineo através dos pulmões. Essa observação de Valsalva permaneceu 
pràticamente ignorada durante cêrca de dois séculos, de forma que, na primeira metade do século XIX, ainda não havia acôrdo quanto à influência ou não da respiração sôbre o fluxo sangüineo. Weber, em 1850, encontrou a explicação dessa discordância de opiniōes; segundo êste autor, a respiração exercia ou não influência sôbre a circulação, conforme a glote se encontrasse fechada ou aberta durante a fase expiratória. Fazendo experiências em si próprio, êle verificou que a compressão do tórax após inspiração profunda e impedimento da expiração, determinava desaparecimento quase imediato do pulso radial, ao passo que, com a expiração livre, nada acontecia. Dez anos depois, Einbrodt, aumentando a pressão pulmonar em animais mediante insuflação de ar na traquéia, determinava as mesmas modificações circulatórias observadas por Valsalva. Sauerbruch, em 1904, interpretou o fenômeno observado por Valsalva como devido a bloqueio da corrente sangüinea pulmonar pela compressão dos pequenos vasos ao nivel dos alvéolos. Humphreys, entretanto, demonstrou, mediante trabalho experimental em cães, que a hipótese de Weber, baseada em raciocinio puramente dedutivo, era verdadeira; Humphreys e col. ${ }^{6}$ puderam demonstrar que, em última análise, o bloqueio da corrente circulatória resulta da compressão das grandes veias intratorácicas, dificultando o enchimento cardiaco. Mediante trabalho radiológico experimental, às mesmas conclusōes chegaram Boerema e Blickman', autores a quem devemos os dados históricos acima referidos.

Boerema e Blickman empregaram o bloqueio circulatório como recurso para o aperfeiçoamento da angiocardiografia; êstes autores conseguiram, mediante êsse recurso, melhor delimitação das estruturas, usando contraste menos concentrado do que os habitualmente empregados e prescindindo dos injetores mecânicos. Teixeira e $\mathrm{Vaz}^{12}$, em nosso meio, chegaram às mesmas conclusões.

Em setembro de 1957 publicamos nota prévia relativa à aplicação do bloqueio circulatório mediante hiperpressão intrapulmonar ${ }^{17}$. Este trabalho foi apresentado ao I Congresso Internacional de Ciências Neurológicas (V Simpósio Neurorradiológico), reunido em Bruxelas em julho de 1957.

Técnica da pan-angiografia - $\mathrm{O}$ aumento da pressão intratorácica é obtido pela insuflação de oxigênio por uma sonda inserida na traquéia do paciente. Essa sonda traqueal deve ser munida de manguito insuflável que, distendido mediante injeção de ar, evita o escape de gás e conseqüente perda de pressão. Para evitar a insuflação excessiva do pulmão adotamos, desde o início, o uso de uma válvula * que, além de regular a entrada de oxigênio, evita, mediante escape de gas, a hiperpressão excessiva que teria lugar caso o paciente tivesse um acesso de tosse.

$\mathrm{O}$ paciente a ser submetido à pan-angiografia recebe, uma hora antes, uma medicação pré-anestésica (fosfato de codeína, Amplictil, Fenergan), em dosagem variável com a idade e o pêso. Para a anestesia é empregado, de preferência, um tiobarbiturato por via venosa. Estando o paciente anestesiado e entubado, é praticada a punção de uma das artérias carótidas primitivas com agulha de calibre relativamente grande (diâmetro interno de

* A válvula aqui referida foi construida pelo Dr. Antônio Pereira de Almeida, do Serviço de Anestesia do Hospital das Clínicas da Fac. Med. da Univ. de São Paulo. 
1,2 $\mathrm{mm}$ para adultos e de 0,8 a $1,0 \mathrm{~mm}$ para crianças). Realizada a punção arterial, conectados eventuais aparelhos de contrôle (electrocardiografia, registro de pressão) e ligado o aparêlho de raios $\mathrm{X}$, o anestesista regula a válvula para $40 \mathrm{~mm} \mathrm{Hg}$ e controla o pulso do paciente. Se a pressão de $40 \mathrm{~mm} \mathrm{Hg}$ não fôr suficiente para fazer desaparecer o pulso arterial, ela é gradualmente aumentada até 50,60 e $70 \mathrm{~mm} \mathrm{Hg}$. Pressão maior não tem sido necessária na generalidade dos casos.

A injeção de contraste é iniciada no momento em que deixa de ser perceptível o pulso arterial. A primeira radiografia é tirada no fim da injeção, ou mesmo um segundo depois, porque, sendo mantida a pressão intrapulmonar, o contraste permanece, sob o ponto de vista radiológico, nas artérias. A fase venosa da circulação encefálica, ainda considerada sob o ponto de vista radiológico, tem início com a abertura da válvula e é a partir dêsse momento que devem ser tiradas as radiografias destinadas ao estudo da circulação de retôrno.

Cuidados e complicações - Considerando os perigos da hiperpressão intrapulmonar em portadores de pneumopatias, os pacientes têm sido submetidos a contrôle radiográfico do tórax antes e depois da pan-angiografia. Um dos pacientes (caso 27), cujo tórax não fôra radiografado por inadvertência, apresentou, coincidentemente, pneumotórax e enfisema subcutâneo logo após a pan-angiografia; por motivo ainda desconhecidos, o pulso arterial, neste caso, só se tornou imperceptível à palpação quando a pressão intrapulmonar atingiu $110 \mathrm{~mm} \mathrm{Hg}$; a seqüência evolutiva não exigiu cuidados especiais, tendo o pneumotórax e o enfisema regredido por completo no prazo de 4 dias. $\hat{E}$ interessante assinalar que nenhuma afecção pulmonar pôde ser demonstrada neste paciente após a reabsorção do pneumotórax; êste fato demonstra que mesmo o contrôle radiológico não constitui medida de eficácia absoluta para prevenção de acidentes; excessiva distensão do parênquima pulmonar em conseqüência da elevada pressão intratorácica pode ter sido a causa da complicação neste caso. Ulteriormente, ocorreu mais um caso em que fôra omitida a radiografia prévia do tórax, mas o paciente nada apresentou de particular.

Temendo distensão excessiva do parênquima pulmonar, particularmente nos pacientes de musculatura flácida e naqueles curarizados pela succinilcolina com o fito de evitar sobrecarga de drogas anestésicas, foi adotado, a princípio, o uso de um colête contensor. Ulteriormente, foi abolido o uso de succinilcolina durante a injeção do contraste, o que veio reduzir o emprêgo do colête.

Desconhecendo ainda os efeitos da isquemia resultante do bloqueio circulatório sôbre o miocárdio anormal, julgamos prudente não submeter à pan-angiografia os pacientes portadores de afecções cardíacas.

Indicações - A pan-angiografia cerebral, permitindo a visibilização a um só tempo de todo o sistema vascular encefálico, tem indicação, a nosso 
ver, em todos os casos em que seja suspeitado o comprometimento vascular e que não tenham sintomatologia focal. A maior indicação dêste exame reside, todavia, nos casos em que é suspeitada a existência de aneurismas arteriais, casos em que há grande vantagem no exame angiográfico de todo o sistema arterial encefálico, dada a possibilidade de serem múltiplos os aneurismas intracranianos e considerada a necessidade que tem o cirurgião de conhecer o estado da circulação intracraniana, a fim de planejar com segurança o ato cirúrgico.

Indicação não menos importante da pan-angiografia cerebral reside nas dificuldades, não muito raras, para a obtenção de angiografia do sistema vértebro-basilar mediante punção de artéria vertebral, punção essa particularmente difícil em crianças.

Poderíamos incluir ainda, como indicação da pan-angiografia cerebral, a vantagem de obter imagens mais nítidas graças à menor diluição da substância radiopaca.

Contra-indicações - Não nos ocuparemos aqui das contra-indicações comuns da angiografia cerebral, válidas também como limitação ao emprêgo da pan-angiografia. Trataremos apenas das restrições específicas dêste método, ou seja, daquelas relacionadas com a hiperpressão intrapulmonar e com as modificações circulatórias que esta acarreta.

A pan-angiografia deve ser formalmente contra-indicada em pacientes com pneumopatias; o parênquima lesado, menos distensível e menos elástico que o tecido pulmonar normal, é passível de rotura pela insuflação forçada de oxigênio.

Outras restrições ao emprêgo da pan-angiografia cerebral são constituídas pelas afecções cardíacas. O coração normal suporta a isquemia resultante do bloqueio circulatório por tempo mais prolongado do que o requerido para a realização do exame. Esta tolerância do miocárdio à isquemia foi demonstrada experimentalmente e comprovada agora em nossos pacientes. Mas um miocárdio lesado ou um coração que funciona em regime de sobrecarga poderiam ressentir-se do déficit sangüíneo, mesmo de curta duração. A limitação ao emprêgo do método em todos os cardíacos talvez constitua um exagêro, principalmente tendo em vista que Boerema e, entre nós, Teixeira e col. utilizaram métodos semelhantes para o estudo angiocardiográfico de pacientes com cardiopatias.

A pan-angiografia não deverá ser feita em casos nos quais, clìnicamente, existam sinais de insuficiência circulatória cerebral; é claro que, em tais circunstâncias, qualquer diminuição do fluxo cerebral poderá ser prejudicial.

O colapso da aurícula direita ocasionado pela distensão pulmonar, constituindo um obstáculo ao enchimento cardíaco, determina estase venosa na grande circulação. Assim sendo, a pan-angiografia cerebral seria, à primeira vista, contra-indicada em casos de hipertensão intracraniana em virtude da possibilidade de agravamento dessa hipertensão pelo edema cerebral resul- 
tante da estase venosa. Entretanto, considerando a curta duração do bloqueio circulatório exigido para a realização do exame e a possibilidade de operação imediata do paciente caso as circunstâncias o exigirem, resolvemos aplicar o método mesmo em pacientes portadores de hipertensão intracraniana. Nenhum indício de agravamento da sintomatologia após a pan-angiografia foi observado nos 18 pacientes que apresentavam quadro clínico de aumento da pressão intracraniana. Assim, embora o número de casos não seja suficiente para estabelecer conceitos definitivos, a evolução de nossos pacientes parece indicar que a pan-angiografia cerebral não é contra-indicada em casos de hipertensão intracraniana.

\section{CASUISTICA}

Até 30 de setembro de 1957, 40 pacientes foram submetidos à pan-angiografia cerebral, segundo o método e os cuidados acima descritos; dêstes pacientes, 25 pertenciam ao sexo masculino e 15 ao sexo feminino; 33 eram brancos e 7 pardos ou prêtos; a idade variou entre 6 meses e 60 anos.

Quanto ao quadro clínico, 18 pacientes eram portadores de hipertensão intracraniana (14 tumores de natureza e topografia diversas, 3 traumatismos cranianos, 1 caso de hidrocefalia obstrutiva); 11 apresentavam hemorragia subaracnóidea (espontânea, 8; traumática, 3), tendo sido pedida a pan-angiografia cerebral, a fim de verificar a presença, ou não, de afecção vascular de tipo cirúrgico. Dos 11 casos restantes, um paciente apresentava, como manifestação principal, paralisia do nervo oculomotor direito, sugerindo o diagnóstico de aneurisma da carótida interna; 4 apresentavam hemiplegia ou hemiparesia de causa não determinada; dois apresentavam manifestações epilépticas; dois eram portadores de tumor ou tumores infratentoriais sem hipertensão intracraniana; um apresentava granuloma eosinófilo do osso occipital, queixando-se de cefaléia generalizada; o último queixava-se de ruído intracraniano, fazendo supor a existência de malformação angiomatosa.

\section{RESULTADOS *}

Os resultados obtidos nos 40 pacientes foram condensados no quadro 1 .

Em 18 casos tôdas as artérias encefálicas foram contratadas (casos 1, $3,6,8,9,11,12,13,15,16,19,21,27,28,30,34,35,39)$; o aspecto radiológico de um dêsses casos está representado na figura 5 . Nos casos 14 e

* A fim de evitar repetições desnecessárias, a documentação radiográfica dos resultados obtidos foi reduzida a apenas um exemplar de cada tipo de distribuição do contraste no conjunto dos vasos encefálicos. Nos esquemas do poligono de Willis colocados nas reproduções radiográficas estão assinalados, em prêto, segmentos arteriais que não foram contrastados. 


\begin{tabular}{|c|c|c|c|c|c|c|c|c|c|c|c|c|c|c|c|c|c|c|c|c|c|c|c|c|c|}
\hline \multirow[b]{3}{*}{$=$} & \multicolumn{5}{|c|}{ Demptric $\angle$ g } & \multirow{3}{*}{$\begin{array}{l}\text { DrLamosrico } \\
\text { curirco }\end{array}$} & \multicolumn{18}{|c|}{ ARTERTAS COMrnustipas } & \multirow{3}{*}{ 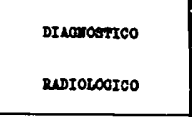 } \\
\hline & & & & & & & \multicolumn{8}{|c|}{ Ipel - jatexel } & \multicolumn{2}{|c|}{ mad. } & \multicolumn{8}{|c|}{ Contze - ieterel } & \\
\hline & EED. & PRarrs. & 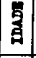 & : & 8 & & 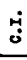 & & & & & & $\omega^{2}$ & & & & : & & & & & & & $\dot{\Delta}$ & \\
\hline 1 & 468574 & I 3116 & 25 & -1 & $b \mathbf{r}$ & Fraven (bonetome?) & + & + & $1+$ & & + & + & + & + & + & + & + & + & + & + & + & + & + & + & demain hoalintorioo * \\
\hline 2 & 468921 & $\begin{array}{|ll|}\mathbf{1} & 3117 \\
\end{array}$ & 42 & 2 & $\mathrm{E}$ & Nower Intre tent. & + & + & + & + & + & 4 & + & + & + & + & + & 4 & \pm & + & 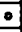 & + & + & + & Ela aroostalle interses" \\
\hline 3 & 474031 & 127439 & 4 & $=$ & br & Mal dortaide & + & + & + & \pm & 4 & 4 & + & + & + & + & + & + & $\cdot$ & + & + & + & + & + & Tormel \\
\hline 4 & 468581 & $P 841016$ & 2 & 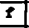 & $D E$ & franes & & + & + & & + & + & + & + & + & $\circ$ & + & + & + & + & + & + & + & $\cdot$ & 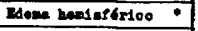 \\
\hline 5 & 476564 & I 3185 & 50 & $=$ & bos & \begin{tabular}{|l} 
Trueor Infre tant. \\
\end{tabular} & + & + & \pm & + & \pm & + & + & + & \pm & + & 0 & + & + & + & - & + & + & $\circ$ & Dormel \\
\hline 6 & 30166 & PS 218 & 23 & - & be & Travel (bomatoan?) & + & + & + & + & \pm & + & + & + & + & + & + & + & + & 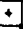 & + & + & + & + & DAde bealeffr100 \\
\hline 7 & 39374 & 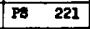 & 27 & - & br & Frevime (bocatones?) & + & + & + & + & + & + & + & + & + & + & $\circ$ & + & + & 4 & + & + & + & + & Yormal \\
\hline 8 & 144001 & $1 \quad 1052$ & 29 & 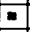 & tre & Foliopele (P.Y.) & + & + & + & + & \pm & + & + & + & + & + & + & + & + & 4 & 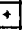 & + & + & + & Mormal \\
\hline 9 & 477668 & 3094 & 12 & 2 & br & Ireor Infres tant. & + & + & + & \pm & + & + & + & + & + & + & + & + & + & + & +1 & + & + & + & Fidrooufalle interne 7 \\
\hline 10 & 469335 & PS 220 & 33 & $=$ & $b \mathbf{r}$ & rraor supsa tont. & + & + & + & + & + & + & + & $\bullet$ & + & 0 & + & + & + & + & - & $\circ$ & + &. & Tuaor supra tent. ** \\
\hline 11 & 473573 & \begin{tabular}{|l|}
1575 \\
\end{tabular} & 18 & 1 & bx & Granulan continos. & + & 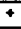 & + & + & $\mp$ & + & + & + & + & + & + & + & + & + & + & + & + & + & Dormal \\
\hline 12 & 253936 & 2341578 & 48 & - & $\mathrm{px}$ & $110001+$ treven & + & 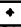 & + & + & + & + & + & + & + & + & + & + & + & + & + & + & + & + & Ioranal \\
\hline 13 & 440047 & 3110 & 20 & - & or & rueor Supre tont. & \pm & + & + & + & + & + & 4 & + & + & + & + & + & + & + & + & + & + & + & rear sepre teat. " \\
\hline 14 & 469594 & 13174 & 10 & - & bs & nmor supse tont. & + & $\uparrow$ & $\bullet$ & + & + & + & + & + & + & + & $\circ$ & $\circ$ & $\circ$ & $\circ$ & $\circ$ & $\circ$ & 0 & $\cdot$ & Reor Supre teat. \\
\hline 15 & 470156 & 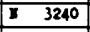 & 17 & 2 & br & rumor Infre tent. & + & 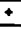 & + & + & + & + & + & + & 4 & + & + & + & + & + & + & + & + & \pm & Ifdrooefalis interne of \\
\hline 16 & 469603 & 3099 & 25 & - & by & Anourie & \pm & + & + & + & + & + & + & + & + & \pm & + & \pm & + & + & + & +1 & + & + & enouritanen miltiplos \\
\hline 17 & 478669 & 437936 & 쏘 & 2 & $b=$ & Tranbose $x$. & \pm & + & + & + & + & + & + & + & + & + & $\cdot$ & \pm & + & + & + & + & + & + & osmal \\
\hline 18 & 43003 & PS 210 & 39 & - & $\overline{\mathbf{p t}}$ & Iranas & + & + & + & + & + & + & + & + & * & + & + & + & + & + & - & - & - & + & Iorand \\
\hline 29 & 469886 & $\begin{array}{|ll|}1 & 3149 \\
\end{array}$ & 23 & \begin{tabular}{|l|l|}
$\mathbf{P}$ \\
\end{tabular} & 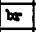 & 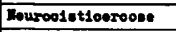 & + & + & + & \pm & + & + & + & + & + & + & + & + & + & + & + & + & + & + & Iormal \\
\hline 20 & 370916 & 13114 & 39 & $=$ & $b x$ & Apeureicese & + & + & + & + & - & $\circ$ & 0 & + & + & - & + & + & + & + & - & 0 & 0 & + & Iormel ** \\
\hline 21 & 478539 & 127920 & 14 & 1 & br & Nevor Supre tent. & + & + & + & + & + & + & + & + & + & + & + & + & + & + & + & + & + & + & Sunor Supre tent. \\
\hline 22 & 372916 & 127777 & 47 & $\$$ & a & Anourdion 1,-7. & + & + & + & + & + & + & + & - & + & - & + & + & + & 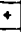 & + & + & + & $\cdot$ & Tormal \\
\hline 23 & 45577 & \begin{tabular}{|ll}
8 & 234 \\
\end{tabular} & 24 & - & br & Aseourien & + & + & + & + & + & + & + & - & + & 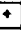 & + & + & + & + & 0 & + & + & $\cdot$ & Formal \\
\hline 24 & 480402 & \begin{tabular}{|l|} 
\\
\end{tabular} & 42 & - & $b \mathbf{r}$ & C1st10050000 IV V. & + & + & + & + & + & + & + & 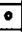 & + & + & - & - & • & - & - & $\circ$ & $\circ$ & $\circ$ & Bldrooefalla betesas of \\
\hline 25 & 4094 & $7 \quad 3131$ & 60 & - & $b x$ & Fromboes 1. & + & + & + & \pm & + & $\cdot$ & $\circ$ & + & + & + & - & - & • & + & • & 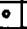 & $\circ$ & + & Tranboes do $A$ ? \\
\hline 26 & 5484 & \begin{tabular}{|l|}
$\quad 28231$ \\
\end{tabular} & 26 & - & br & Ancurie & \pm & + & + & + & 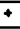 & \pm & \pm & + & + & + & - & + & + & + & $\leftarrow$ & + & + & 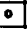 & Yormal \\
\hline 27 & 480738 & \begin{tabular}{|l|l|}
$\quad 3202$ \\
\end{tabular} & 38 & - & bre & Treor Intre tont. & + & + & + & + & + & + & + & - & + & + & + & + & + & + & + & + & + & - & Fidrooufalla interen of \\
\hline 28 & 479214 & \begin{tabular}{|l|}
13189 \\
\end{tabular} & 60 & $=$ & $b x$ & Irooafal1a & + & + & \pm & \pm & + & + & + & + & + & + & + & + & + & + & + & + & + & $\cdot$ & Eldrooefalla interna \\
\hline 29 & 478023 & \begin{tabular}{|l|}
27804 \\
\end{tabular} & 19 & 2 & br & Dod lopela (0.11.) & + & + & + & + & + & + & + & 0 & + & + & + & + & + & $\uparrow$ & 0 & + & + & 10 & Toranal \\
\hline 30 & 486824 & I 3160 & 52 & - & pa & Anowert ine & + & + & + & + & + & + & + & + & + & + & - & + & + & + & + & + & + & 7 & lomal \\
\hline 31 & 481380 & \begin{tabular}{|l|}
8343206 \\
\end{tabular} & 50 & 2 & $8 x$ & D. Teconerar & + & + & + & + & 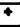 & - & + & + & + & + & - & + & + & + & - & - & + & 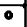 & aximal \\
\hline 32 & 50230 & \begin{tabular}{|l|l|} 
P3 & 241 \\
\end{tabular} & 30 & - & Br & Fraven & +1 & + & + & + & + & 0 & + & $\circ$ & + & • & $\bullet$ & • & $\bullet$ & + & • & 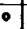 & 0 & - & aranel \\
\hline 33 & 481496 & 3234 & 33 & -1 & $m=$ & 40. Vesopulas & + & 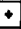 & + & + & + & - & + & 0 & + & • & 0 & -0 & 0 & + & $\bullet$ & $\circ$ & - & 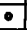 & Iasmal \\
\hline 34 & 481593 & Ore 1977 & 16 & 2 & br & Atwereceos & + & + & 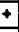 & + & 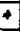 & + & + & + & + & + & + & + & + & 4 & + & + & + & $\cdot$ & Tox \\
\hline 35 & 401915 & 3188 & 20 & 8 & br & bovertes & + & + & + & + & $\uparrow$ & + & + & + & + & + & 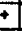 & + & † & 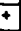 & + & + & + & 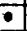 & Tormal - hementomen \\
\hline 36 & 1926 & 3226 & 25 & 8 & $b$ & heos sayre tont. & + & + & 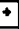 & $\bullet$ & $\bullet$ & - & + & $\uparrow$ & † & + & & + & + & + & $\bullet$ & $\circ$ & + & $\cdot$ & Theor dupera tout. " \\
\hline 37 & 0479 & 126326 & 33 & $=1$ & $\mathbf{E}$ & Amearles & + & + & + & \pm & + & + & + & + & + & † & $\theta$ & 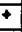 & + & + & * & 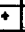 & + & $\bullet$ & Anowis C.I. \\
\hline 36 & 470780 & 329 & 37 & - & 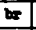 & Neor Infra tant. & \pm & $\bullet$ & + & + & + & + & 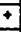 & + & + & + & 0 & $\bullet$ & 0 & 0 & - & + & + & 0 & Elarooetalis intenge \\
\hline 39 & 72918 & & & 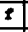 & $\mathbf{b}$ & rowor suppere tant. & + & + & + & + & + & + & + & - & + & & & $\uparrow$ & & & t & + & + & - & Noner supere tont. " \\
\hline 40 & 75723 & 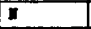 & 20 & 1 & $m$ & Treos toupuentent. & 1 & 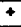 & + & + & 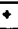 & 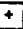 & + & 0 & & & & & & & & & & - & 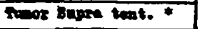 \\
\hline
\end{tabular}

Quadro 1 - Resultados da injeção de contraste por via carotidea em pacientes submetidos a bloqueio circulatório. Leganda: $A_{1}$, segmento pré-comunicante da artéria cerebral anterior; $A_{z}$, segmento pós-comunicante da artéria cerebral anterior; $B$, tronco basilar; C.I., artéria carótida interna; C.A., artéria comunicante anterior; $P_{1}$, segmento pré-comunicante da artéria cerebral posterior; $P_{2}$, segmento pós-comunicante da artérai cerebral posterior; $M$, artéria cerebral média; $V$, artéria vertebral; H.I.C., hipertensão intracraniana; H.M., hemorragia meningea; * confirmado por verificação cirúrgica ou necroscópica; ** verificado por ato cirúrgico ou necroscópico, não tendo sido confirmados os achados angiográficos.

24 (fig. 6) tôdas ou parte das principais artérias contralaterais não foram contrastadas, mas vasos de menor calibre em seu território de distribuição apareceram em todo o hemisfério cerebral correspondente. Nos casos 4 e 22 (fig. 7) o contraste penetrou nas artérias do sistema carotídeo contralateral e na cerebral posterior de ambos os lados, mas não apareceu a imagem do tronco basilar. No caso 25, pelo contrário, foram contrastados os 
ramos da carótida ipsolateral e o tronco basilar, não tendo sido visibilizados os ramos da carótida contralateral (fig. 8).
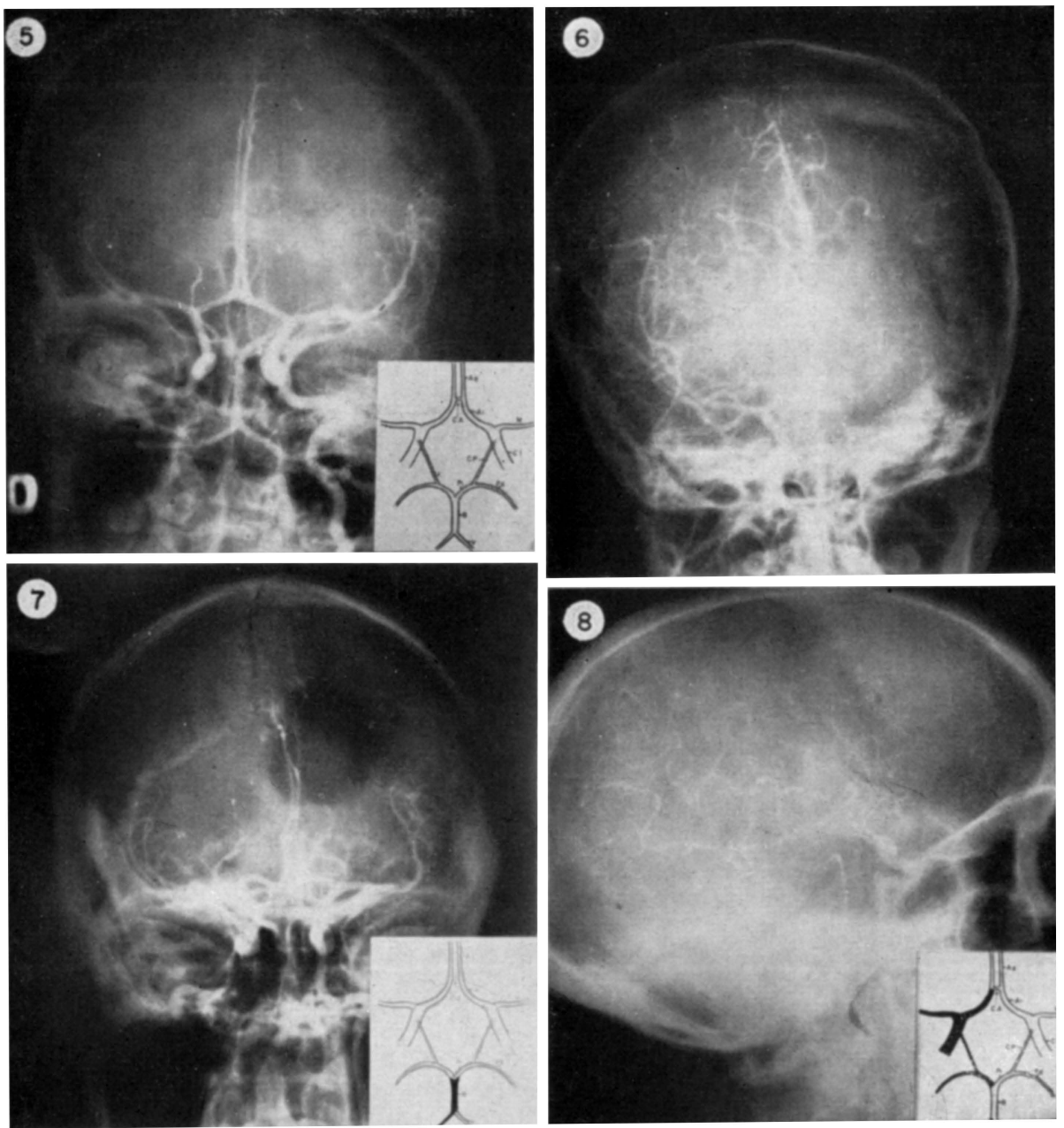

Fig. 5 - Caso 9. Pan-angiografia cerebral: enchimento de tôdas as artérias do poligono de Willis, assim como de seus ramos aferentes e eferentes. $O$ mesmo aspecto foi observado nos casos 1, 3, 6, 8, 11, 12, 13, 15, 16, 19, 21, 27, 28, 30, 34, 35, 39.

Fig. 6 - Caso 14. Pan-angiografia cerebral: no hemisfério contralateral foram contrastadas apenas artérias de calibre reduzido, o que sugere atraso da exposicão radiográfica. Aspecto semelhante foi observado no caso 24.

Fig. 7 - Caso 4. Pan-angiografia cerebral na qual não apareceu a imagem do tronco basilar. Aspecto semelhante foi observado no caso 22.

Fig. 8 - Caso 25. Pan-angiografia cerebral: enchimento do tronco basilar e de seus ramos, ao passo que as artérias do território carotídeo contralateral não foram contrastadas. 
Nos casos 32 e 33 apareceram apenas os ramos da carótida ipsolateral, o segmento pós-comunicante das artérias cerebral anterior contralateral e cerebral posterior ipsolateral (fig. 9); portanto, nestes casos, apesar da hipotensão arterial, não foi visibilizado qualquer outro território vascular além daquele em que o contraste foi injetado. O segmento pós-comunicante das artérias cerebral anterior contralateral e cerebral posterior ipsolateral, que foram visibilizadas nestes casos, não são achados de monta, pois êstes segmentos vasculares podem ser visibilizados em carotidoangiografias comuns, isto é, mesmo quando não seja determinada hipotensão arterial. Em trabalho anterior ${ }^{18}$, no qual foram analisados os resultados da carotidoangiografia em 700 pacientes, obtivemos a visibilização dêstes segmentos em $50 \%$ dos casos, aproximadamente.

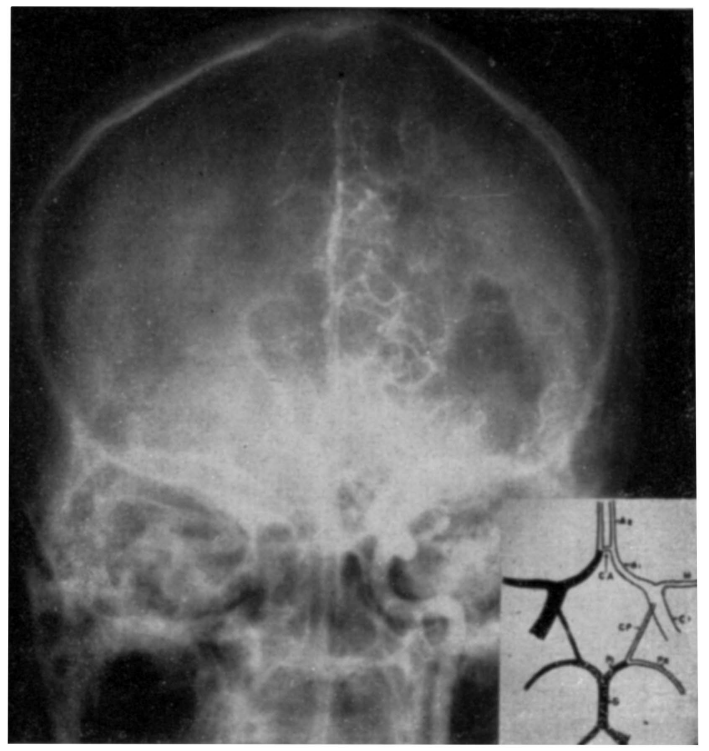

Fig. 9 - Caso 32. Neste caso não foi conseguida a pan-angiografia cerebral; o segmento pós-comunicante das artérias cerebral anterior contralateral e cerebral posterior ipsolateral, visibilizados nestes casos, apareceram em aproximadamente $50 \%$ dos 700 casos analisados em trabalho anterior ${ }^{18}$. Aspecto semelhante foi observado no caso 33.

Nos 15 casos restantes, maior ou menor segmento arterial do hemisfério contralateral ou da parte posterior do poligono de Willis não foi contrastada. Assim, nos casos 2, 23 e 29 (fig. 10), não foi contrastada a artéria comunicante posterior contralateral; nos casos 7, 17, 26 e 27 (fig. 11), não apareceu a imagem da carótida interna contralateral; no caso 5 (fig. 12), as artérias carótida interna e comunicante posterior contralaterais não foram contrastadas; no caso 10 (fig. 13), não foram visibilizados o tronco basilar, a artéria comunicante posterior e o segmento pré-comunicante da artéria cerebral posterior contralaterais; no caso 18 (fig. 14), não apareceram as artérias comunicante posterior e cerebral posterior contralaterais; no caso 20 (fig. 15), não foram contratadas as artérias basilar, comunicante posterior e cerebral posterior contralaterais; no caso 31 (fig. 16), não foram contrastadas a carótida interna, a comunicante posterior e o segmento pré-comunicante 
da artéria cerebral posterior contralaterais; no caso 36 (fig. 17), não foram contrastadas a comunicante posterior e o segmento pré-comunicante da artéria cerebral posterior; no caso 38 (fig. 18), não foram contrastadas as artérias carótida interna, cerebral média, cerebral anterior e a comunicante
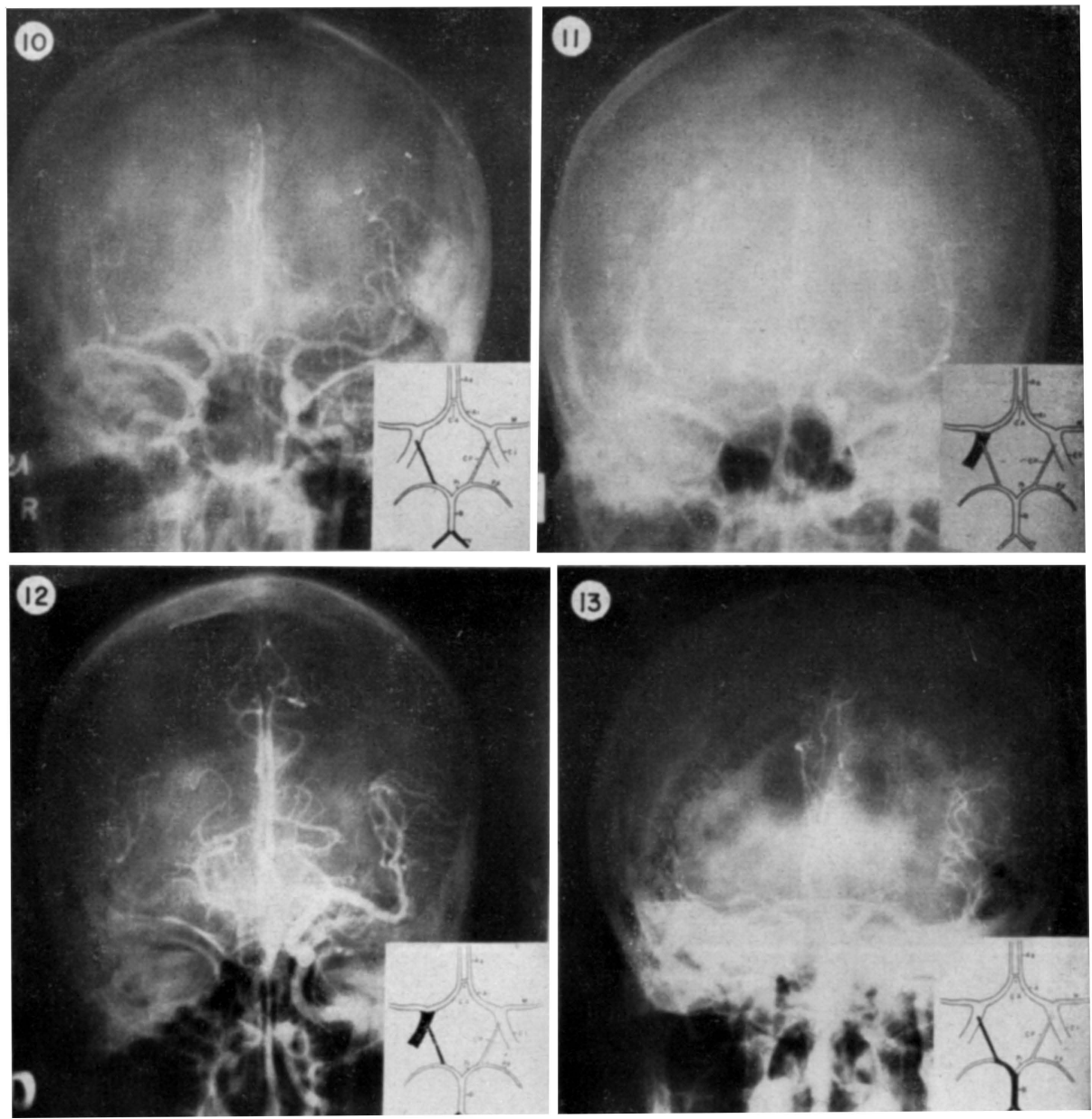

Fig. 10 - Caso 23. Pan-angiografia cerebral na qual a artéria comunicante posterior contralateral não é visivel. Aspecto semelhante foi observado nos casos 2 e 29.

Fig. 11 - Caso 26. Pan-angiografia cerebral na qual a carótida interna contralateral não é visivel. Aspecto semelhante foi observado nos casos 7,17 e 37.

Fig. 12 - Caso 5. Pan-angiografia cerebral na qual não foram contrastadas as artérias carótida interna e comunicante posterior contralaterais.

Fig. 13 - Caso 10. Pan-angiografia cerebral: ausência das imagens do tronco basilar, da artéria comunicante posterior e do segmento pré-comunicante da artéria cerebral posterior contralaterais. 
posterior contralaterais; finalmente, no caso 40 (fig. 19), as artérias não contrastadas foram a comunicante posterior e a cerebral posterior contralaterais.
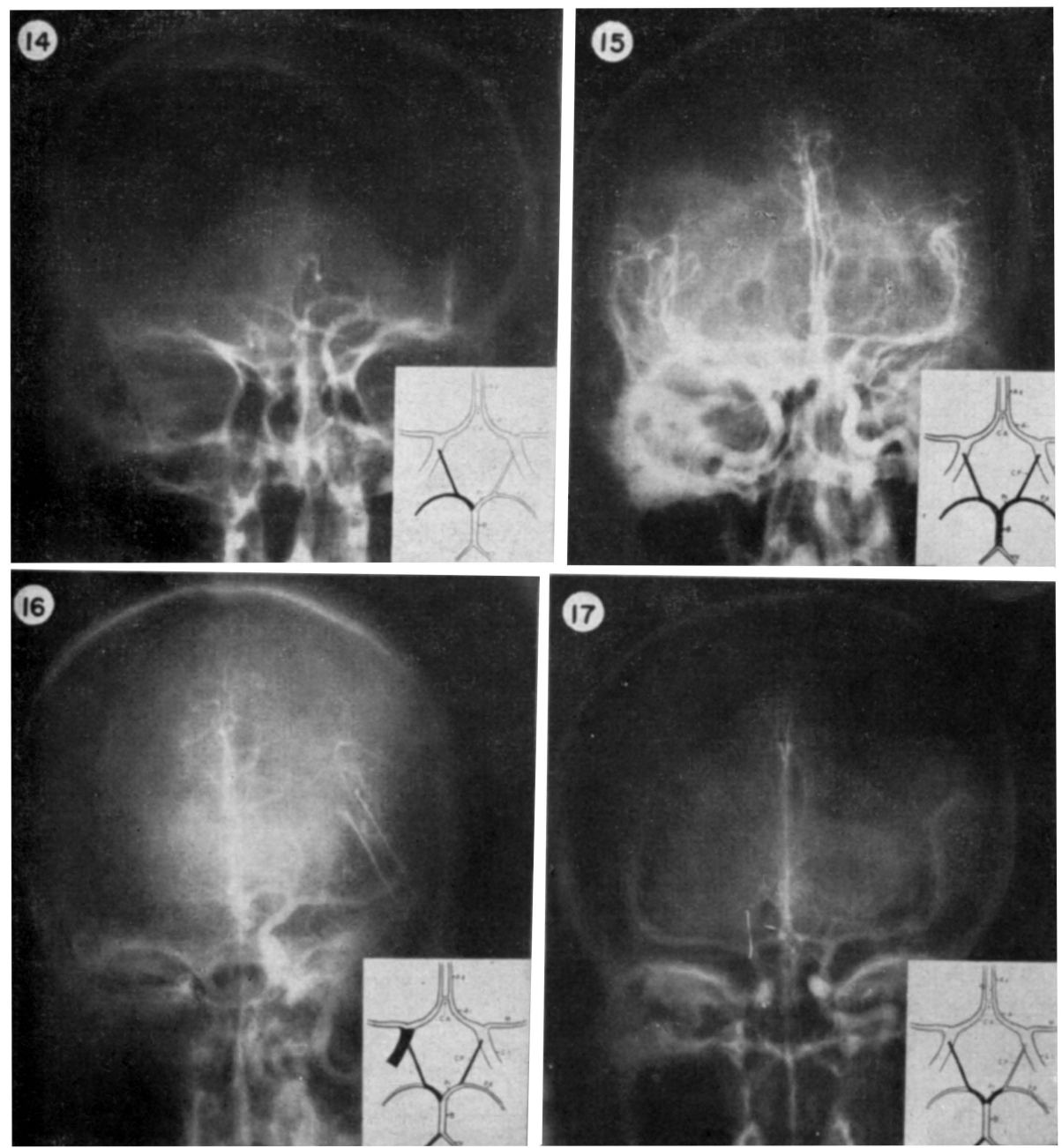

Fig. 14 - Caso 18. Pan-angiografia cerebral: ausência das imagens da artéria comunicante posterior e da artéria cerebral posterior contralaterais.

Fig. 15 - Caso 20. Pan-angiografia cerebral: ausência das imagens do tronco basilar $e$ das artérias comunicante posterior e cerebral posterior de ambos os lados.

Fig. 16 - Caso 31. Pan-angiografia cerebral: ausência das imagens das artérias carótida interna e comunicante posterior, assim como do segmento pré-comunicante da artéria cerebral posterior contra-laterais.

Fig. 17 - Caso 36. Pan-angiografia cerebral: ausência das imagens da artéria comunicante posterior e do segmento pré-comunicante da artéria cerebral posterior. 

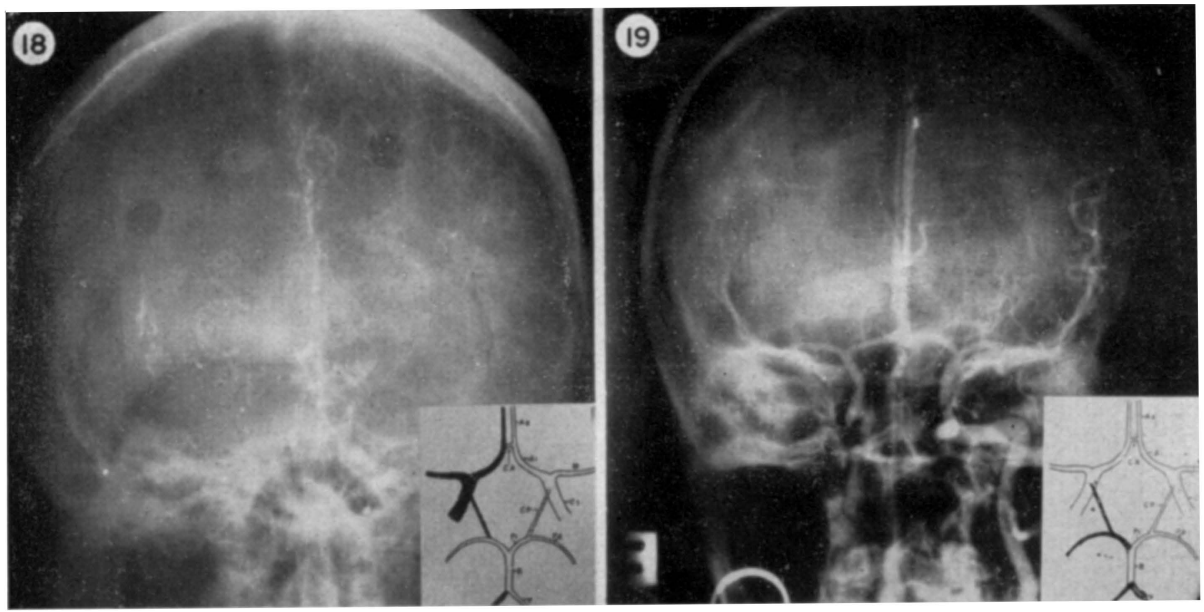

Fig. 18 - Caso 38. Pan-angiografia cerebral: ausência das imagens da artéria carótida interna contralateral e de seus ramos ao passo que as artérias do sistema vértebro-basilar são bem visiveis.

Fig. 19 - Caso 40. Pan-angiografia cerebral: ausência das imagens das artérias comunicante posterior e cerebral posterior contralaterais.

Analisando êstes resultados verifica-se que, à exceção dos casos 32 e 33 (fig. 9), a pan-angiografia foi conseguida em todos. A falta de uma ou outra parte do leito arterial do hemisfério do lado oposto ao da carótida na qual o contraste fôra injetado ou do sistema vértebro-basilar pode ser devida, seja à oclusão arterial, seja a um defeito na cronometragem das exposições radiográficas. Êste é, a nosso ver, o fator mais plausivel na generalidade dos casos. Não será visível na radiografia a porção terminal em caso de exposição precoce; na eventualidade de exposição retardada não será visivel, na radiografia, a porção proximal da artéria. Nos casos 14 e 24, por exemplo, a falta das grossas artérias eferentes do polígono de Willis e a existência de artérias de menor calibre ocupando tôda a área de projeção do hemisfério contralateral parece indicar que tenha havido um atraso na exposição do filme aos raios $\mathrm{X}$.

No caso particular da artéria comunicante posterior, a impossibilidade de identificação de sua imagem não significa obrigatòriamente que ela não tenha sido contrastada (figs. 16 e 17); dada sua topografia esta artéria pode ser inaparente devido à superposição de sua imagem àquela da carótida interna (na incidência sagital) ou à da outra comunicante posterior (na incidência lateral). Na eventualidade de ausência das imagens das artérias da parte posterior do polígono e boa contrastação dos ramos da carótida contralateral (caso 20) ou de situação oposta (caso 25), a falta dêste ou daquele grupo arterial pode ser explicada pela insuficiência ou ausência do respectivo ramo comunicante, dada a freqüência das variações anatômicas 
e anomalias do polígono de Willis nas quais são envolvidos seus ramos comunicantes.

Nos casos 32 e 33 (fig. 9) não foi conseguida pan-angiografia cerebral, apesar de nossa insistência repetindo injeçōes de contraste e modificando algumas condições técnicas; em ambos os casos foram feitas quatro injeções de contraste, modificando a cada tentativa a velocidade de injeção do contraste e o momento do disparo do aparêlho de raios $\mathrm{X}$.

$O$ insucesso na obtenção de pan-angiografia cerebral nestes casos não pode, pois, ser atribuído a mero defeito na cronometragem das exposições. Oclusão ou ausência dos ramos comunicantes do polígono de Willis também não podem ser responsabilizadas nestes casos porque tanto a artéria comunicante posterior ipsolateral quanto a comunicante anterior são claramente visiveis nas radiografias. Outros fatôres poderiam ainda ser lembrados para explicar a não obtenção de pan-angiografia nestes casos, mas a verdade é que a causa verdadeira ainda nos escapa.

\section{COMENTARIOS}

Restringiremos nossas considerações à matéria compreendida na segunda parte dêste trabalho, pôsto que a primeira parte é constituída principalmente de dados contidos em publicação anterior.

A princípio, quando por meio de drogas ganglioplégicas pretendiamos induzir acentuada hipotensão arterial nos pacientes, a fim de comprovar a hipótese que haviamos formulado, percebemos logo que, caso o conseguíssemos, teriamos apenas obtido a interpretação de um fenômeno raramente observado. A complexidade, a morosidade e as dificuldades para levar a pressão arterial aos níveis desejados indicavam claramente que, com as drogas existentes, o método jamais poderia ter aplicação prática. O bloqueio circulatório mediante hiperpressão intrapulmonar, pelo contrário, revelou-se método prático, rápido e seguro, passivel de entrar na rotina angiográfica dentro do âmbito de suas indicações. De fato, hoje em dia, diante de um caso de hemorragia meníngea, eventualidade que demanda a exploração radiográfica de tôdas as artérias intracranianas, não vacilamos quanto à indicação da pan-angiografia cerebral.

As vantagens do método são bem ilustradas nas figuras 20 e 21 . A figura 20 (caso 16) mostra, a um só tempo, um aneurisma da carótida interna direita, um da carótida interna esquerda e um terceiro da artéria cerebral média esquerda; a figura 21 (caso 28) mostra pan-angiografia cerebral de uma criança de 6 meses de idade, idade em que as artérias do sistema vértebro-basilar dificilmente podem ser visibilizadas mediante punção direta de artéria vertebral.

Tendo em mente que o bloqueio circulatório resulta da compressão do coração direito e das veias cavas, hesitamos em empregar a hiperpressão intrapulmonar na vigência de hiperpressão intracraniana. Temíamos aumentar a pressão intracraniana e agravar o estado dos pacientes pela estase venosa na grande circulação. Considerando, porém, a curta duração dêsse 

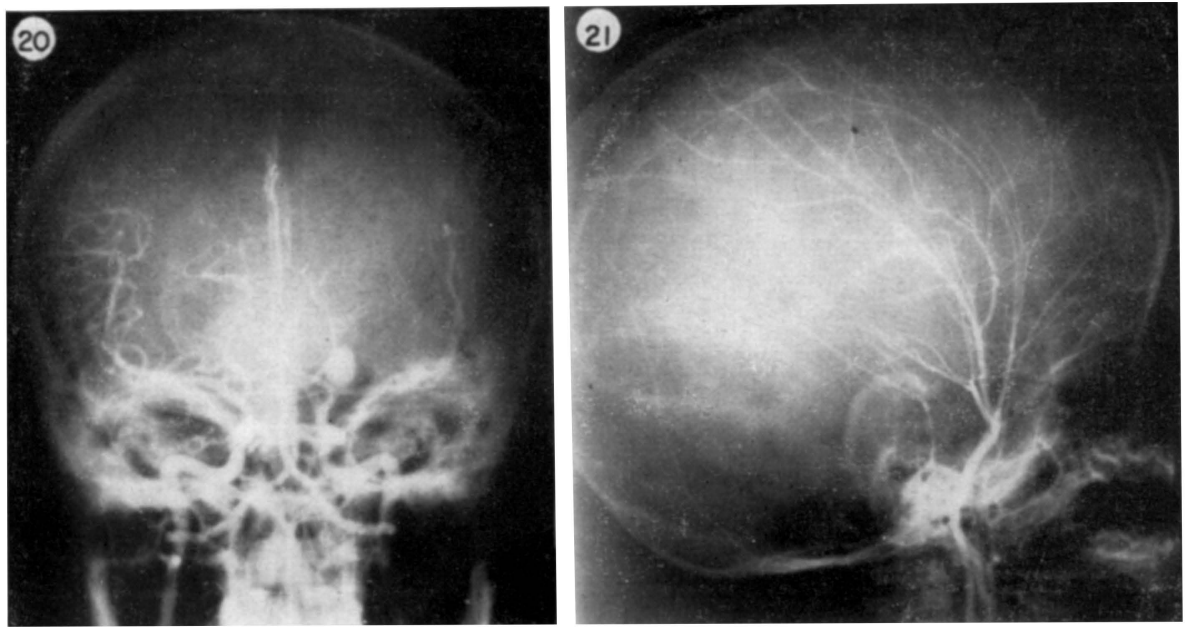

Fig. 20 - Caso 16. Pan-angiografia cerebral mostrando, a um só tempo, aneurismas das artérias carótida interna direita, carótida interna esquerda e cerebral média esquerda.

Fig. 21 - Caso 28. Pan-angiografia cerebral permitindo a visibilização radiografica do sistema vértebro-basilar em crianca de 6 meses de idade.

regime de estase venosa e a possibilidade de operação imediata no caso de agravamento dos pacientes, decidimos usar o recurso da pan-angiografia mesmo nos casos de hipertensão intracraniana. A experiência vem mostrando que a pan-angiografia não determina modificação apreciável também no estado dêsses pacientes. Porém, em portadores de pneumopatias, a pan-angiografia cerebral é formalmente contra-indicada. Esta é a razão pela qual foi instituído desde o início o contrôle radiológico do tórax antes de submeter qualquer paciente à pan-angiografia cerebral.

Analisando os resultados obtidos com a pan-angiografia cerebral verifica-se que, na maioria dos casos, injetado o contraste na vigência do bloqueio circulatório, foram visibilizadas tôdas ou a maior parte das artérias encefálicas. Em alguns casos, a pan-angiografia só foi conseguida na segunda ou terceira tentativa. Êste fato mostra que há fatôres técnicos e individuais inerentes ao paciente que podem interferir com a distribuição do contraste. Dos fatôres individuais, a tosse, muito freqüente durante a distensão pulmonar, compromete nìtidamente a pan-angiografia quando ocorre durante a injeção do contraste. A codeína na medicação pré-anestésica e a insuflação lenta dos pulmões têm influído, ao que parece, no sentido de evitar êsse inconveniente. Apesar dos cuidados mencionados e de anestesia laringotraqueal, também empregada para evitar a tosse, a eliminação definitiva dêsse inconveniente ainda não foi conseguida. $O$ fator individual mais importante a ser considerado em caso de insucesso na obtenção da pan-angiografia é, a nosso ver, a impermeabilidade dos ramos comunicantes do polígono de Willis. Não se trata, entretanto, de condição sine qua non para que a pan-angio- 
grafia cerebral seja viável, pôsto que, em alguns de nossos casos, há indícios de que a substância radiopaca injetada na carótida tenha penetrado na artéria vertebral do mesmo lado via artéria subclávia (fig. 22).

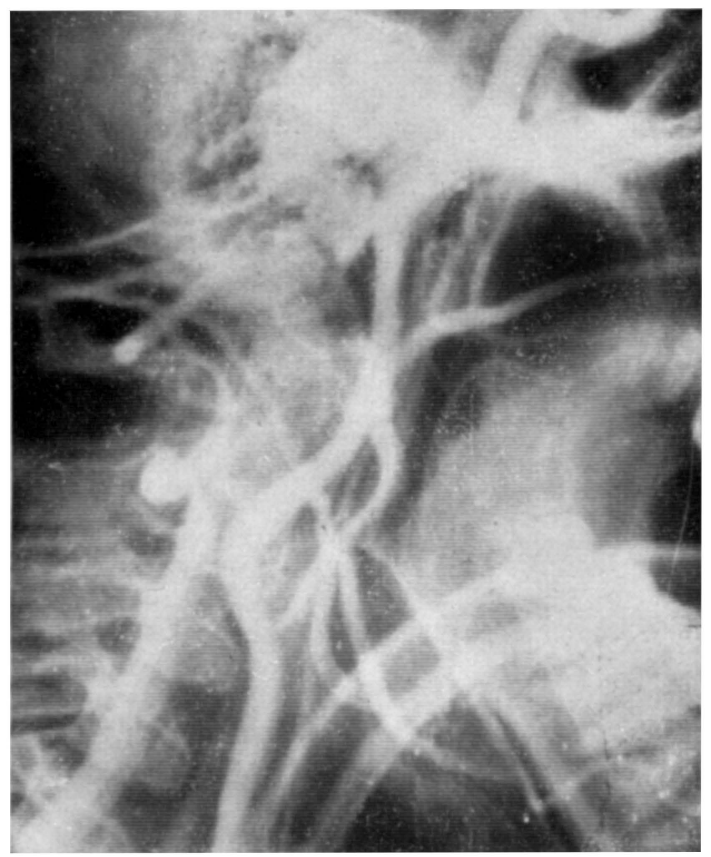

Fig. 22 - Caso 13. Uma fase da pan-angiografia cerebral mostrando enchimento da artéria vertebral em sentids caudo-rostral.

Consideranđa a acentuada redução da pressão arterial e de fluxo sangüíneo provocada pela hiperpressão intrapulmonar, torna-se fàcilmente compreensivel que o contraste se difunda em todos os sentidos em conseqüência da pressão exercida na seringa.

\section{RESUMO E CONCLUSõES}

Este trabalho visa a demonstrar que é possível, mediante redução da pressão arterial, contrastar todos os vasos encefálicos pela substância radiopaca injetada em uma das carótidas.

Para promover a baixa da pressão arterial, lançamos mão, em primeiro lugar, das drogas ganglioplégicas; entretanto, não tendo fornecido resultados satisfatórios, êsse método foi abandonado. O bloqueio da corrente sangüínea por hiperpressão intrapulmonar, método sistematizado por Boerema e Blickman como recurso para melhorar as qualidades técnicas das angiocardiografias, pareceu-nos ideal para o objetivo a que visávamos. Quando a pressão intrapulmonar atinge valores próximos de $60 \mathrm{~cm}$ de água, a pulsação das artérias torna-se imperceptível à palpação e a pressão arterial cai a niveis muito baixos; em tais condições, se uma substância radiopaca é injetada em uma das carótidas, por ser a pressão arterial muito baixa, a 
pressão exercida na seringa fará com que o contraste penetre em todos os vasos encefálicos.

A injeção de $15 \mathrm{ml}$ de Nosylan a $35 \%$ na vigência de hipotensão arterial mostrou-se plenamente satisfatória; em 38 dos 40 pacientes que constituem a casuística dêste trabalho tôdas ou quase tôdas as artérias encefálicas foram visibilizadas mediante injeção de contraste por via carotídea.

Tratando-se de método simples e seguro, julgamos que êle poderá vir a ser usado em tôdas as eventualidades clínicas que exijam o exame angiográfico de ambos os territórios carotídeos e do sistema vértebro-basilar.

\section{SUMMARY AND CONCLUSIONS}

\section{Cerebral pan-angiography}

Cerebral pan-angiography is the name we suggest for the visualization of all intracranial blood vessels, after injection of contrast medium in one of the carotid arteries.

In 1957, in a preliminary report to this paper - read at the V Symposium Neuroradiologicum (First Congress of Neurologic Sciences - Brussels, Belgium) and published in Arquivos de Neuro-Psiquiatria (15:211-214, September, 1957) - we gave the theoretical bases of the method. Spontaneous filling of the vertebro-basilar system in a number of cases of carotid angiography suggested that a marked drop in blood tension and blood flow could be the responsible factor for the phenomenon. These circulatory changes might have their origin in a reflex elicited in a hypersensitive carotid sinus. Whatever the true mechanism of the arterial hypotension it was our feeling that deliberate cerebral pan-angiography might be accomplished by lowering the patient's blood pressure during the injection of the opaque substance.

Ganglioplegic drugs failed to bring hypotension to desired levels: the effects of these drugs are not strictly proportional to the dosis in every case; there is interference of individual factors so that increasing the amount of hypotensive drugs might be dangerous in many cases. In order to avoid accidents this method was discarded.

The blood stream blocking by means of intrathoracic hyperpressure, as described by Boerema and Blickman, seemed to be the method of choice for the task we had in mind. When the intrathoracic pressure reaches $50-60$ $\mathrm{mm}$. Hg. the blood tension falls to a very low level and pulsating of arteries disappears. Intracarotid injection of $15 \mathrm{ml}$. of $35 \%$ Nosylan soon after the arterial pulse is discontinued is proving quite satisfactory. Table 1 shows detailed data concerning the results we obtained in a series of 40 patients.

In 38 patients out of this series intrathoracic hyperpressure lowered the cerebral blood circulation to such levels as to allow the contrast medium to flow into vessels not belonging to the territory of the injected artery, even against the normal blood stream. In the remainder two patients nothing but the branches of the injected carotid artery was contrast filled, 
despite the intrathoracic hyperpressure; we still do not know why intrathoracic hyperpressure failled to produce in these two cases the hemodynamic conditions required for contrast filling of blood vessels out of the field of the injected carotid artery.

As soon as intrathoracic pressure is released the contrast medium leaves the arteries following the normal stream of cerebral circulation. We have not yet detailed data concerning the venous phase of pan-angiography. For such a purpose rapid serial equipment is required.

Although this report is based on a small amount of cases we believe that cerebral pan-angiography is a harmless and safe method and it can be employed in every patient in which examination of both carotid fields and arteries of the vertebro-basilar system is required as, for instance, when intracranial aneurysms are suspected.

\section{BIBLIOGRAFIA}

1. BOEREMA, I.; BLICKMAN, J. R. - Reduced intrathoracic circulation as an aid in angiocardiography. An experimental study. J. Thor. Surg., 30:129-142 (agôsto) 1955. 2. CURTIS, J. B. - Rapid serial angiography: preliminary report. J. Neurol. a. Psychiat., 12:167-183, 1949. 3. GREITZ, T. - A radiologic study of the brain circulation by rapid serial angiography of the carotid artery. Acta Radiologica, supl. 140, 1956. 4. HAMBY, W. B. - Intracranial Aneurysms. Charles C. Thomas. Springfield (Illinois), 1952. 5. HEYMANS, C. - Action of drugs on carotid body and sinus. Pharmacol. Rev., 7:119-142 (março) 1955. 6. HUMPHREYS, G. H.; MOORE, R. L.; MAIER, H. C.; APGAR, V. - Studies of the jugular, carotid and pulmonary pressure of anesthetized dogs during inflation of the lung. J. Thor. Surg., 8:553, 1938 . 7. KRAYENBUHL, H.; RICHTER, H. R. - Die zerebrale Angiographie. Georg Thieme, Stuttgart, 1952. 8. LINDGREN, P.; TORNELI, G. - Blood pressure and heart rate responses during carotid angiography with sodium acetrizoate: an experimental study in cats. Apresentado ao $5^{\circ}$ Simpósio Neurorradiológico Internacional. Resumo publicado por Excerpta Médica, volume especial: 127 (julho) 1957. 9. MONIZ, E.; ALVES, A. - L'importance diagnostique de l'arteriographie de la fosse postérieure. Rev. Neurol., 2:91-96 (julho) 1933. 10. PORTUGAL, J. R.; SAMPAIO, P. - Contribuição ao estudo anatômico e radiológico das artérias da fossa posterior. J. Bras. de Neurol., 6:301-318 (setembro-dezembro) 1954.11. SHAPIRO, S. K.; PEYTON, W. T. - Spontaneous thrombosis of carotid arteries. Neurology, 4:83-100 (fevereiro) 1954. 12. TEIXEIRA, J.; VAZ, A. - O princípio da circulação reduzida em angiografia (nota prẽvia). Rev. Bras de Cir., 32:4 (outubro) 1956. 13. TORKILDSEN, A.; KOPPANG, K. - Notes on the collateral cerebral circulation as demonstrated by carotid angiography. J. Neurosurg., 8:269278 (maio) 1951. 14. van der ZWAN, A. - Angiographic diagnosis of vertebral artery thrombosis. J. Neurol., Neurosurg. a. Psychiat., 17:189-190 (agôsto) 1954.15. ZACLIS, J. - Angiografia vértebro-basilar retrógrada acidental. Arq. Neuro-Psiquiat., 13:357-362 (dezembro) 1955. 16. ZACLIS, J. - Persistência da anastomose carótido-basilar: a propósito de um caso revelado pela angiografia cerebral. Arq. Neuro-Psiquiat., 13:351-356 (dezembro) 1955. 17. ZACLIS, J.; ALMEIDA, A. P. Pan-angiografia cerebral (nota prévia). Arq. Neuro-Psiquiat., 15:211-214 (setembro) 1957. 18. ZACLIS, J.; LONGO, P. H.; MATTOSINHO FRANÇA, L. C. - Distribuição do contraste em angiografias cerebrais: angiografias carotideas com enchimento do tronco basilar. Arq. Neuro-Psiquiat., 15:97-124 (junho) 1957. 